\title{
Knowledge management in the territorial intelligence
}

\author{
Víctor Hugo Medina García, Luis Leonardo Rodríguez Bernal and Flor Nancy Díaz Piraquive
}

\begin{abstract}
This article introduces the concepts of territorial intelligence, knowledge management and intellectual capital with the purpose of establishing the links in the multidisciplinary scientific field, whose sustainable development is a territory and its subject is a community with its intellectual capital. In order to achieve this purpose, a few tools were applied that provide the method Catalyse, making an analysis of the data (qualitative, quantitative and space) of the information through the use of a software generating as a result some profiles defined, by grouping them according to their socio-economic characteristics and environmental, based on the number of answers frequency found, by creating categories or classes. In this way, the socio-territorial variables are related, with a geo-statistics analysis that serves to support the researcher's knowledge, the actors and their governance, in making decisions about the planning and territorial intelligence development. Finally some conclusions and recommendations about the participation of the different actors (social, scientific, economic and political administrative) are presents, which requires the management of knowledge with the aim of generating a contribution to the post-conflict period.
\end{abstract}

Keywords - Intellectual capital, knowledge management, territorial intelligence, catalyse method.

\section{Introduction}

The territorial intelligence is an alternative proposal and a critical approach to the sustainable development, which manages territorial projects concluded in a participatory manner with the Community in accordance with the multisectoral policies development, with the aim of building collective intelligence generating an intellectual capital according to their knowledge.

In a time of transition, as the one in which Colombia is involved, it is looking for a new model of sustainable development of policy expectations in which there are better nation-State relationships of the territorial actors, that address critically the socio - cultural, economic and environmental issues, with a territorial prospective, that takes into account with a globalization view through the participation of the social, scientific, economic and political - administrative actors, within which it is necessary to ensure the management of the knowledge based on the value of the intellectual capital of the individuals or groups decision-makers that have data, information and knowledge, with the purpose of achieving a level of effectiveness and efficiency stronger players in the organizations through some

Víctor Hugo Medina García, Luis Leonardo Rodríguez Bernal

Universidad Distrital Francisco José de Caldas

Bogotá, Colombia

Flor Nancy Díaz Piraquive

Universidad Católica de Colombia, Bogotá
Innovations series way, maximizing the performance and minimizing the costs, in order to achieve a development level of a sustainable territorial intelligence.

This article presents a model and a method of knowledge management in the territorial intelligence. It finishes including a Bogota case study in which the socio-territorial variables are related by doing a geostatistics analysis, through which it is concluded that it is important to develop projects with the participation of all actors in the territory, in order to contribute to the social development generating welfare, through the use of the social sciences, basic sciences and by applying engineering methodologies.

\section{Fundamentation}

The territorial intelligence is a critical approach to multisectoral policies for sustainable development. In this regard, it turns out to be an alternative of a model that builds territorial projects arranged with the community participation, using scientific knowledge and information - communication technologies, seeking to produce a collective intelligence.

On the other hand, it is also considered as a tool for the management of the knowledge of the territorial public and private actors, which interact through a social fabric with the purpose of seeking a development of the territory sustainable [1]. Through the territorial intelligence, it is explored an integral development of the territory based on the solution of all the interrelated problems through dialog, negotiation, cooperation and the coordination of actions, where interact the actors involved in the decision-making, seeking an optimization of the resources and a better social welfare in the community.

It is necessary to clarify the following concepts, so that there was a tendency to confuse territorial intelligence, intelligent territory and finally the territorial engineering. The territorial intelligence is an knowledge instrument at the service of the generator actors of the development sustainable of the (social approach) territories; while the intelligent territories are instrument of the government, whose structure and public services are efficient and interactive, environmentally sustainable and committed with the cultural and historical elements, looking for a competitive (territorial approach) city [2].

On the other hand, we have the territorial engineering, that has an interdisciplinary and systematic approach, which promotes and focuses the necessary changes in a regional and local level, with the purpose of improving the welfare and quality of the actors life, through the land management, development management, (engineering approach) [3].

Therefore the territorial intelligence can be defined as a "field multidisciplinary scientific in which the object of study is the sustainable development of a territory and the subject is a territorial community"[4], in which an intelligent territory is the one that is capable of responding to the social cohesion, economic 
competitiveness and environmental sustainability supported on the techniques and procedures transdisciplinary and interdisciplinary that through the knowledge management generated a sustainable development economically and environmentally sustainable, in a territory of the global context.

Within the territorial intelligence, there is a matrix and its phases for the transformational construction of the territorial intelligence by means of which it is an transformation and logic order of the territory, the simultaneous processes of construction, of the ideas into projects, people in subject and spaces in territories [5], which are developed in some systems, as shown in the following figure:

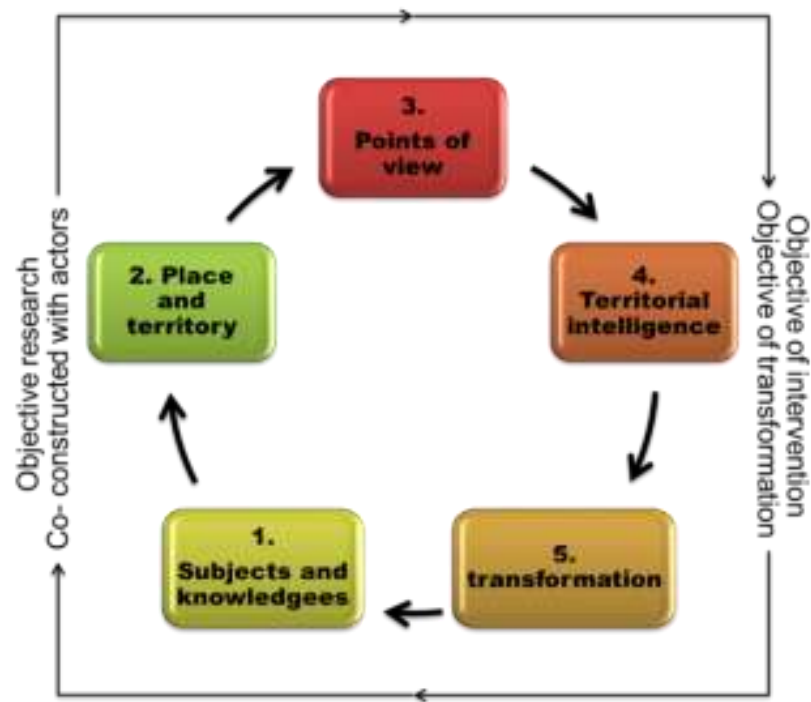

Figure 1. Matrix and phases for the construction of territorial intelligence transformation. The figure adapted from territorial intelligence - team TAG possible territories, 2011

The first three systems are consecutive; they possess an abstract and common vision about what the territory is. The actors involved in its development (society), the sciences involved with their knowledge that share knowledge facilitating the transformation of the ethical and cultural expressions (Academy), harmonizing the socio - political (company), in the implementation management of the citizen's mandate (State), creating awareness among the community and its natural environment. Some elements related with the first three consecutive systems are described below:

1) Subjects and knowledge: they are the combination knowledge transformation of understandings (popular, scientific, political, business, and others).

2) Place and territory: it determines a territory as a socio-natural and cooperative construction where the power relationships are carried out, according to its scale, its time and its space to develop some objects and actions in certain territory.

3) Views: taking into account the confluence of six points of view: pillars of independence (knowledge, ethics and aesthetics), powers (the social power, economic power and political power), distinction (the culture capital and economic capital), social (the actors, places and processes), triad pillars of Regulation (the community, the market and the State), Environment and its resources natural [6].
To close the cycle, it appears that in the two consecutive systems, their vision is more analytical because it considers its theoretical, scientific and professional bases, which support the synergy between reality and what has happened in generating results, and projects that transform and develop a territory.

Some elements related with the two following consecutive systems are described below.

4) Territorial intelligence: it contributes to build subject, projects and territories simultaneously, in an event according to a society considering their expectations, desires and dreams based on scientific criteria with the scheme of logical frame to identify projects in a territory (engineering approach).

5) Transformation: it is a triple simultaneous construction process between the subject, the territories and their projects. At this stage the intervention of the State in the implementation of the development plans and land management.

Finally, the cycle surround is started again, by improving the socio economic environment surroundings in a territory, referring again to the subjects and their transformed knowledge with new knowledge.

As conclusion, is can be told that the base of the territorial intelligence is knowledge product of different points of views or social, economic and environmental approaches that help to the transformation of the territory. Therefore, the systems previously exposed are related to the study that is the sustainable development of a territory, and its subject of study is a territorial community, through the transformation of its territory.

At the same time, in the territory social, scientific, economic and political - administrative actors participate because they necessarily manage their knowledge based on the value of its intellectual capital (individuals or groups decision-makers). But, taking in that the events occurred since the local territorial knowledge (territorial capital), requires to pay greater attention to

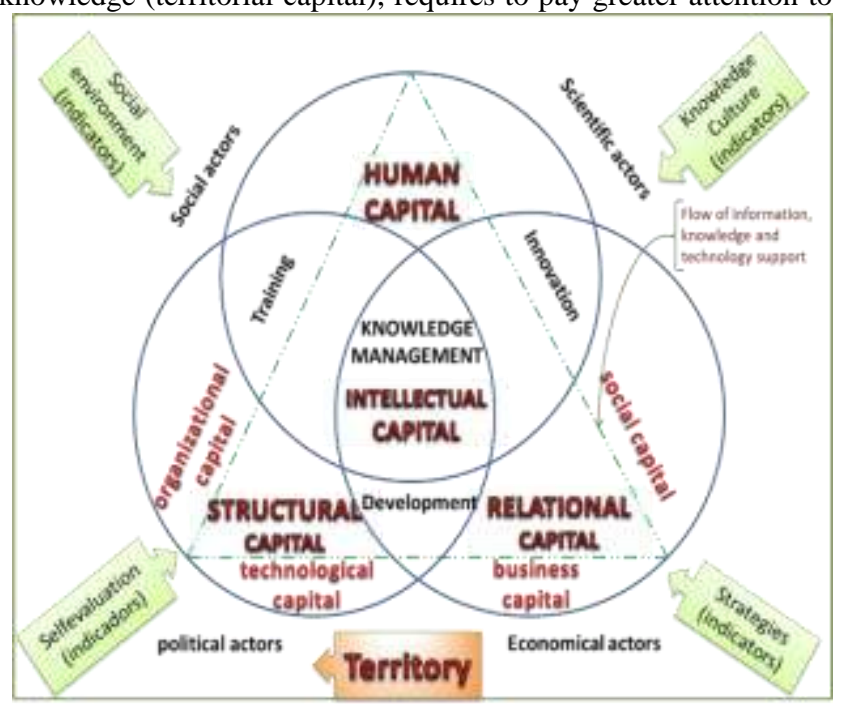

its articulation with the experience and accumulated knowledge (intellectual capital) from the actors. This is a couple of capitals with organization and its knowledge networks [7].

Figure 2. Model of actors in the territorial intelligence supported by the management of the knowledge. Source: Authors. 
Likewise, the organizational scheme varies in each of the following entities: the society, the academy, the company and the state, but all of them need the knowledge management based on the intellectual capital (stock of knowledge) of the decisionmakers actors in each organization, with a common purpose that is the intelligent sustainable development The intellectual capital is part of the knowledge assets (KA), which are all those resources, tangible or intangible, that are incorporated or are consisted of knowledge, which allow the execution of a process that is developed for the value creation [8]. The combination of permanent assets of existing knowledge with new knowledge enables the creation and the exploitation of opportunities in the regions.

Furthermore, the knowledge management of its intellectual capital contains the productive and competitive aspects that can be recorded and measured generating greater benefits for each of their organizations. Accordingly, the organizations (companies, academic, business and state) are concerned with preserving the talent immersed (intellectual capital) in their entities [9].

Knowledge management is a logical course that begins with the identification, creation, capture, sharing, storage and transfer of knowledge (tacit or explicit), generating competitiveness and effectiveness at the level of the organizations with the essential aim, to achieve the goals of the Organization.

Thus, the knowledge management is considered as a set of management disciplines that shows the intellectual capital as an asset of the organization, using technological tools and components that enable the knowledge sharing to achieve the specific objectives of the Organization, which recognized and highlighted the importance of uniting efforts, for achieving the main knowledge objectives [10].

It is then, the implementation of a knowledge management model, where the Community applies a new organizational scheme, supported in the four pillars that society provides the academy, the company and the state, which converge in the generation of a knowledge management system within a territory.

This collective knowledge management can be analyzed in the framework of a territorial intelligence. In addition, the spatial component is very important in the conscience geographically diverse science fields and in the development policies. The problems of the society have a relationship and an appropriation important within the Territory (territoriality). In every project, the collective management of the territorial knowledge (knowledge management) are important and the life quality is focused on the development strategy [11].

\section{Catalyse Method}

For the development of this proposal there was used some of the Catalyse Method hardware, which is a diagnosis process, of evaluation and accessible observation to the local actors, of the territorial sustainable development. The method provides instruments to encourage the cooperation and the participation of the involved actors that takes the sustainable development of the community as a main target in its territory, this by means of the public participation (survey's) and the information analysis.

The method provides instruments to encourage the cooperation and the participation of the actors involved in the same community and serves to manage in an efficient way the projects that try to achieve the territorial sustainable development.
The information obtained by means of the surveys tries to investigate the situation of every person, its difficulties and its needs, with the intention of identifying and grouping in association profiles, the needs according to the groups of people, in the territory object of study [12].

As a result, the Catalyse method looks that the data analyses (qualitative, quantitative and spatial) and its information produce different knowledge between the investigators, the actors and its governance, for a sustainable development of the community.

To reach this intention, the methods of statistical and spatial analysis of the protocols of information, management, evaluation and geographical information systems were applied which use the information and the communication skills [13].

For the development of the method different software of a sequential way was used: the first one used to reach a qualitative and quantitative analysis of the surveys made in field, was a PRAGMA, the second one, charged to develop a dimensional coordinated system of the answers analyzed previously was an ANACONDA. Finally, there was used the program that visualizes

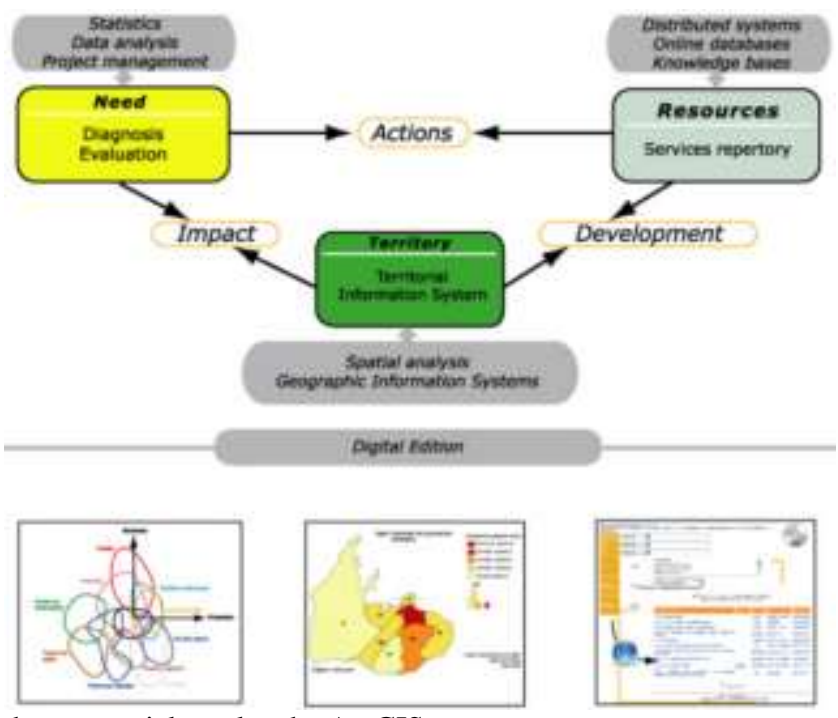

the geospatial results, the ArcGIS.

The Catalyse method integrates the information of the needs, the resources and the territory from an actions point of view by measuring the impact and the development that are generated in a society and its environment, as shown in the following graph.

Figure 3. Catalyse method diagram. Source: http://www.territorialintelligence.eu [14].

The Catalyse method offers some hardware that by means of the statistical elements, information protocols data, the information management and evaluation and by the geographical information systems made them fundamental for the territorial intelligence development, bearing in mind that they generate integration, cooperation and participation principles of the different actors of the territorial sustainable development.

\section{Variables}

The surveys refer to the social, economic and environmental dimensions that are valued and categorize on a scale, by means of such variables like: the sector of the city, the class of age, the genre, the offensive smells, the source of bad smells, the school 
environmental, the civil participation, the parks and the green spaces, the garbage and solid compilation, the coverage compilation, the families at home, the families in the hearth, the monthly salary, the household income, the educational level, the affiliation to health and the health for contamination. This survey was applied in the Tunal Oriental, Tunjuelito and Venecia neighborhood.

\section{v. Methodology}

Using the Catalyse method hardware had several analyses realized in the process which generates products like the following ones:

a) Obtaining the information in the field and survey digitization by generating Booleans reporting tables in the PRAGMA program.

b) Importation and interpretation of this information to find similar structural tendencies, clouds (classes of typology) integrated that makes the analysis in third dimension (social, economic and environmental) in the ANACONDA program.

c) Finally, the geo-referentiation of the results was obtained by means of the ArcGIS program.

\section{vi. Results}

The different results in every stage of the methodology [15] were obtained by the questions made and incorporated into the PRAGMA program that generates Booleans data that were deposited in the ANACONDA program for the generation of classes, which represent a few special characteristics of a group of people whose answers have a similar tendency. As a result, ten classes were gotten.

Some of them were similar; therefore, they were regrouped in this way: the classes 1, 2 and 3, the class 4 and 5, the class 6 , the class 7, the class 8 and 9 , and the class 10 . The classes unions are shown in the following figure.

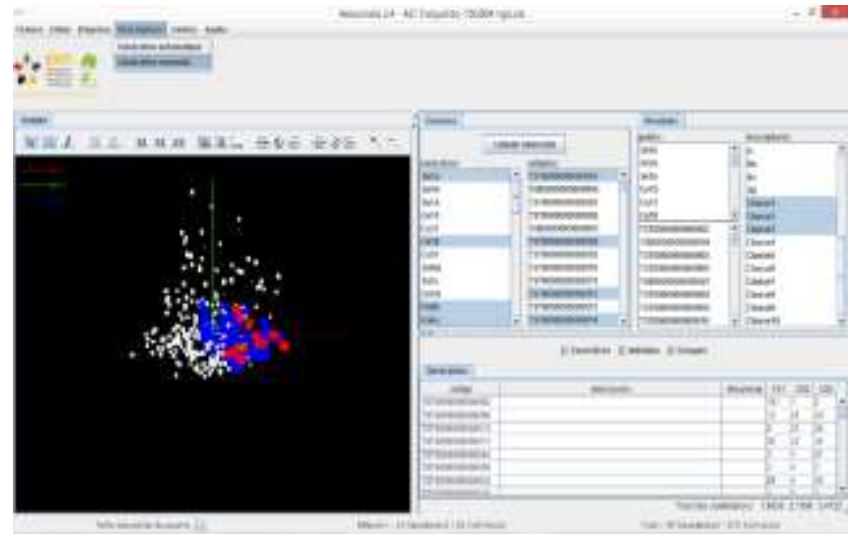

Figure 4. Union of classes. Source: Authors

Each class represents a dimension, in this case the class $(\mathrm{x})$ is the red that represents the environmental part, while the class (y) of blue color shows the economic part and the green class $(\mathrm{z})$ focuses the social part of the analysis.

At the same time, it can be observed a relationship between classes with a precision of 10 , with a standard deviation of around 0.2 , with which, the limit is created which represents the group being the Cartesian class (economic, social and environmental), where classes are grouped, as it is shown below:

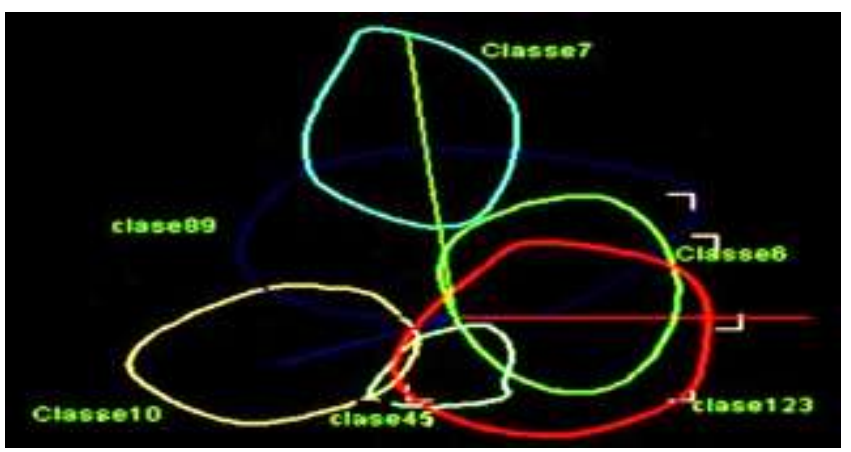

Figure 5. Final display of classes. Source: Authors.

This qualitative analysis aims to study the diversity of association, allowing to discover the relationships between the variables observed, the relations between the individuals tested as well as the relationship that may exist between these variables and the individuals comparatively. The result obtained is the profile for each generated class that has its own characteristics, depending on the frequencies of responses found.

As an example of this result, this characterization by classes can be defined as follows: Class 1, its largest grouping and importance is affected by pollution, after is the disposal of garbage regulate. The Class 2 , it is very important first by the educational level, secondary, by the quality of the park and green areas and by the predominance of response that are dominated by women. The Class 3 has a little trend marked on the coverage and collection of the wastes categorized as bad. The Class 4 has a profile slightly marked by the number of people living in the house which is greater than 10 , the main source of unpleasant odors are the sewers of the sector, which by accumulated waters generated especially during the rainy season. The Class 5 has its greatest grouping and importance in the collection trash and disposal which is good, they are characterized by a low monthly salary, the parks and green areas of the sector in which they live has a good or excellent characteristics and the main number of response are obtained from men. Finally, this class 6 whose profile is characterized by having good life conditions, with revenues of more than two legal minimum wages, they have higher studies, they do not perceive odors, so they do not affect their health, they have affiliation to health, with prepaid medicine.

Based on the data previously obtained and taking it as a reference the classes found, geo-spacialization studies made with the program ArcGIS, show six categories, from which only three of them were chosen, this is illustrated below:

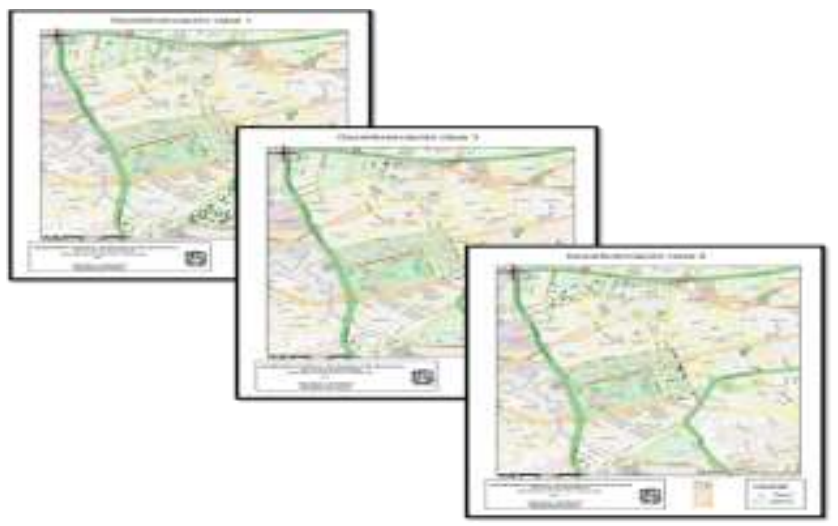

Figure 6. Georeferenciation classes. Source: Authors. 


\section{Conclusions}

The knowledge management in the territorial intelligence aims to provide a method and some tools that strengthen the relationship between society, University, company and State in order to reach an intelligent sustainable development.

The knowledge management arises from the integration of organizations with its intellectual capital in a town, where it's territorial information, its analysis, its tools and its collaboration processes, that are managed through the information and communication technologies.

The knowledge management strengthens the actors' participatory territorial culture such as: society, University, company and State in order to optimize their territorial powers for getting a justice and sustainable development.

The territorial engineering is reached through an integral inter and transdisciplinary vision of the knowledge about the social and territorial dynamic, their development policies and with its territorial cooperation.

Finally is necessary add that, the geospatial information focuses the socio economic, territorial and environmental intervention, improving the process of taking decision and citizen participation, benefiting the governance, which brings a great strengthening by contributing in the research-action in the University, therefore it contributes to the social justice and to the intelligent sustainable development.in a territory.

\section{Acknowledgments}

Work done in collaboration with the Distrital University "Francisco José de Caldas" of Bogotá D.C., Colombia, (http://www.udistrital.edu.co).

\section{References}

[1] J. Girardot. ENTI. Recovered June 20, 2014, de www.teeritorialintelligencie.eu

[2] Red de Ciudades de Ciencia e Innovación. Hacia un territorio inteligente Smart Innovation. Vila do conde, Galicia-norte, Portugal. 2013.

[3] Boville, Belén; Sánchez-González, Diego. Planificación Territorial y Desarrollo Sostenible en México, Perspectiva Comparada / Planning and Sustainable Development in Mexico, Comparative Perspective. Universidad de Barcelona-Universidad Autónoma de Tamaulipas. p. 465. 2007.

[4] H. Bozzano. Inteligencia territorial. Teoría, métodos e iniciativas en Europa y América Latina. la Plata, argentina: Universidad de la Plata. Equipo TAG territorios posibles, May 2011. Pág. 110. 2011.

[5] De Sousa Santos, Boaventura. Una epistemología del sur: la reinvencion del conocimiento y la emancipacion social, clacsosiglo XXI, Buenos Aires. 2009.

[6] H. Bozzano, H. San Cristobal con Intelligence Territorale. Recovered May 5, 2015 de Slideshare:

http://es.slideshare.net/caenti/inti13-san-cristobal-con-intelligenceterritoriale

[7] Y. Bertacchini, P. Maurel, P. Deprez, R. Plant, «Spatial information \& communication arrangements: a contribution to territorial intelligence. », International Journal of Emerging Trends in Computing and Information Sciences, ISSN 2079-8407, http://www.cisjournal.org, Vol. 4 No. 1, January. 2013.

[8] G. Schiuma, A. Lerro. Knowledge-based dynamics of regional development: the intellectual capital innovation capacity model. Int. J. Knowledge-Based Development, Vol. 1, Nros. 1/2, p. 39-52. 2010.
[9] Clavijo. Cómo retener el talento. Revista Gerente, No. 156, primer semestre. 2011.

[10] A. Arbonies. Conocimiento para Innovar. Vol. 1, 2a. ed. Madrid: Díaz de Santos. 2006.

[11] S. Gonzales. Inteligencia territorial; principios y métodos. Recovered 2014 from: http://www.iberopublicaciones.com/andador/ articulo_detalle.php?id_volumen=2\&id_articulo $=27$.

[12] J. Girardot \& C. Masselot. Coordination Action of the European Network of Territorial Intelligence. Recovered 2006 from: http://www.academia.edu/5083287/CAENTI_Coordination_Action _of_the_European Network_of_Territorial_Intelligence.

[13] H. Bozzano. El método Stlocus, relaciones con el método Catalyse. Formación IT Colombia, ciencia con y para la gente, 67. Bogotá, Colombia. 2013.

[14] Inteligencia territorial. Recovered July 29, 2015. http://www.territorial-intelligence.eu/portail/site/

[15] L. Cely, C. Martínez \& L. Rodríguez. Documento de trabajo. Inteligencia territorial, medio ambiente y condiciones socioeconómicas. Bogotá. 2015.

\section{About authors(s)}

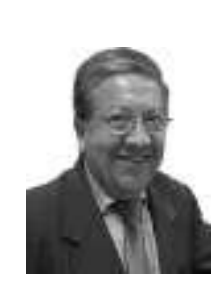

Víctor Hugo Medina García. He is $\mathrm{PhD}$ degree in Computer Engineering from the Pontificia of Salamanca University, DEA Languages, Systems and Software Engineering and Master in Computer Science at the Politécnica University of Madrid in Spain, Specialist in Marketing from the Rosario University and Systems Engineering of the Distrital University "Francisco José de Caldas" of Colombia. He is currently a researcher and senior lecturer at the Faculty of Engineering at the Distrital University "Francisco José de Caldas" in Bogotá Colombia, where he is Extension Director of Engineering Faculty, he was Director of Engineering Doctorate. It is also professor in UNIR - International University of the Rioja and he was coordinator, associate professor and visiting professor in Computer Engineering from the Pontificia of Salamanca University campus of Madrid - Spain. His area of work and research is knowledge management and software engineering.

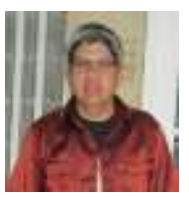

Luis Leonardo Rodriguez. He is student of $\mathrm{PhD}$ in Engineering from the Distrital University, Master in Economic from Andes University and Catastral Engineering of the Distrital University "Francisco José de Caldas" of Colombia. He is currently proffessor at the Faculty of Engineering at the Distrital University "Francisco José de Caldas" in Bogotá - Colombia. His area of work and research is knowledge management and geografic information systems.

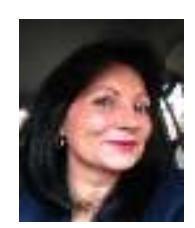

Flor Nancy Díaz Piraquive. She is $\mathrm{PhD}$ degree in Computer Engineering, program Society of Information and Knowledge from the Pontificia of Salamanca University, Specialist in Formulation and Evaluation of Projects and Project Management Systems at the University of Rosario, Economist of the Catholic University. He is currently a researcher and senior lecturer at the Faculty of Engineering at the Catholic University in Bogotá - Colombia, It is also professor in UNIR - International University of the Rioja His area of work and research is project management. 